\title{
reviews
}

\section{Working Therapeutically with Women in Secure Mental Health Settings}

Nikki Jeffcote \& Tessa Watson (eds) London: Jessica Kingsley, 2004,

£19.95 pb, pp. 224.

ISBN: $1-84310-218-8$

This is an excellent collection of papers for professionals working together in secure mental health settings for women. The publication of the national strategy Women's Mental Health: Into the Mainstream (Department of Health, 2002) mapped out gender-specific service development for the next decade and beyond. However, the map had been drawn in the absence of specific evidence about treatment efficacy. There was little professional consensus on what type of service actually worked for which particular group of women; the policy implementation guidance recommended that women's mental health should become an integral element in the training of all staff and managers, within every organisation but there was no research and little agreement about the types of training required. This book is therefore timely and a valuable resource in a relatively new but rapidly developing field.

The content addresses a range of clinical, political, social, training and management issues for women's secure services. The excellent introduction by the two editors, Nikki Jeffcote and Tessa Watson, lays out some of the key themes of the book, including the multidisciplinary nature of the work, the importance of care pathways into secure services and out of them again, and the impact of early experience and trauma on the development of adult therapeutic relationships. A feminist perspective underwrites many of the chapters. It defines the framework within which inequality and disempowerment are addressed; this may not appeal to all readers.

The first section comprises six chapters on 'theory building', the second is focused on 'practice' and the third is a collection of four practical papers on training and 'service development'.

Needs and risk assessment are both addressed in the first section. The chapter by Nikki Jeffcote and Ray Travers on 'thinking about the needs of women in secure settings' helpfully reviews current approaches and the salience of relational issues, making the important link with Bowlby's attachment theory. This is an illuminating description of an overarching theoretical model of care. It is complemented well by Les Petrie's extremely useful and practical chapter in the third section on 'men, women and good practice.' It also provides an appropriate springboard for Gwen Adshead's provocative piece on 'more alike than different: gender and forensic mental health', which draws out the dialectic with characteristic authority; it is refreshing to see the inclusion of an alternative view of gender sensitivity. Tony Maden's chapter on 'risk assessment' addresses the unresolved difficulty of applying the existing risk assessment tools to women when they have all been standardised on male populations. There are no easy solutions here, but his guidance on the use of good holistic clinical risk assessment complemented by some of the existing instruments is helpful.

The 'practice' section includes a series of illuminating case examples to illustrate particular treatment approaches.

Countertransference difficulties experienced by staff are described by Anne Aiyegbusi, in her chapter 'Thinking under fire'. She makes an effective case for clinical supervision for nursing staff, but perhaps misses the opportunity to highlight the need for multidisciplinary reflective practice. There is also a good definitive chapter on the Gender Training Initiative by Sara Scott and Jennie Williams, necessary reading for all staff working in secure services.

I enjoyed this book immensely; it is rich reading and should be accessible on the bookshelves of women's service resource rooms.

DEPARTMENT OF HEALTH (2002) Women's Mental Health: Into the Mainstream. London: Department of Health. http://www.dh.gov.uk/assetRoot/04/07/ 54/87/04075487.pdf

Sarah Davenport Lead Consultant for Women's Secure Services, Guild Lodge, Preston PR3 2AZ

\section{Wyatt's Practical Psychiatric Practice: Forms and Protocols for Clinical Use (3rd edn)}

Richard Jed Wyatt \&

Robert H. Chew

Washington DC: American

Psychiatric Publishing, 2005

$\$ 100.50,240 \mathrm{pp}$ (with CD-ROM).

ISBN: 1585621099

To paraphrase René Magritte, this is not a book. As the title suggests, it is an extensive set of A4-sized sheets for use in everyday clinical practice, ring-bound to allow for easy photocopying. The two sections for clinicians provide basic record-keeping forms and rating scales. The two sections for patients and families provide information about psychiatric disorders and psychiatric medications. It is designed for the American market and so includes medical insurance forms, invoices and a final collection notice for those pesky late payers.

The idea of assembling a comprehensive set of clinical papers is terrific. However, this example sits uneasily with the needs of UK National Health Service practice. Most of the clinician forms are redundant, as trusts will usually have their own proformas. The tick box format of many sections encourages standardised collection of data, but with no tie-in to any database engine to aggregate and analyse the data collected. The rating scales might be useful but are available from other sources. The information for patients and families is admirably thorough, accurate and (on the whole) up to date, but is written in a jargonistic, technical style. I ran some of these sheets through the Flesch Reading Ease test, a standardised scale in which higher scores indicate greater readability. They averaged out at around 20, compared with a recommended level of 60-70 for public information. There is little information about psychological therapies or their effectiveness.

The bundled CD contains electronic PDF files of all the documents in the package. They cannot be altered but if you really want to customise them for your own use, it's the work of a moment to copy the text and paste it into a word processor for editing.

So, can I recommend it for UK practice? Not as it stands, although it provides a useful example of the tools that should be available to every psychiatrist. It might be helpful in private practice, although the difficulty in customising the forms would limit its appeal. I suspect that the patient information sheets might more often be used as aides memoire by the doctor.

Philip Timms Consultant Psychiatrist, START Team, South London and MaudsleyTrust, London

\section{Our Inner World: A Guide to Psychodynamics and Psychotherapy}

\section{S. R. Ahles}

Baltimore: The Johns Hopkins University Press, 2004, f18.00, pb, 335 pp. ISBN: 0-8018-7936-5

This book presents a selection of psychodynamic and developmental theories and a perspective on brief psychotherapy (1025 sessions) that is discussed in terms of 
these theories. Detailed clinical material is used to illustrate the approach. It is a considerable achievement to have covered so much ground and brought so many strands of thinking together, but the result is far from satisfying. To my mind, this is for three main reasons.

Firstly, rather mechanistic, impersonal, language is used to describe and explain highly personal phenomena. This follows from the way in which Ahles regards Freudian structural theory and ego psychology as offering essential descriptive and explanatory concepts. Thus in one of the numerous clinical illustrations he writes, 'Because of the tenuous affective balance within the ego and the tendency for it to be further imbalanced by superego and id forces, Roberta was quite dependent on external sources of positive affect to keep it in balance' (p. 175). Such a description of the internal world appears to conflate physical and psychological modes of explanation. In my view, the numerous diagrams that resemble illustrations of electrical circuitry exacerbate this problem.

Secondly, the linking of a large number of theoretical ideas continually begs the question of what constitutes the bottom line in his psychodynamic perspective. The clinical examples suggest that he regards modifying attachment patterns and 'affective balance' within the ego (largely through the expression of empathy and the provision of explanation) as the essence of psychodynamic work. This perspective is not presented in a critical way.

Thirdly, and to my mind most importantly, there is no discussion of the significance of understanding the 'inner world of the primary process'. Thus, there is only scant reference to psychotic modes of being and relating, and then only as a level of separation-individuation. This serious deficiency is reflected in the relative neglect of the transference and the promotion of explanation over interpretation. Relatedly, none of the clinical examples are of patients with psychotic disorders.

Despite the troubling language and diagrams, the author has usefully summarised a range of psychodynamic ideas and produced an approach to psychotherapy that reads as if it would enjoy a high degree of acceptability among relatively high-functioning patients. However, the sidelining of the transference and the absence of any psychotherapeutic approach to psychosis significantly limits its value as a general psychodynamic text for trainees in psychiatry or psychotherapy.

Leyland C. Sheppard Specialist Registra in Psychotherapy, Nottingham Psychotherapy Unit, 114 Thorneywood Mount, Nottingham NG3 2PZ

\section{Female Genital Mutilation: Treating the Tears}

Haseena Lockhat

London: Middlesex University

Press, 2004, f15.99 pb, 198 pp.

ISBN: 1-898253-90-0

Female genital mutilation is not a subject where neutrality is an option. Twenty years ago Northern European feminists took up the abolitionist cause with fervour. Abolitionists were attacked as culturally insensitive. They, in turn, accused their attackers of inappropriate cultural relativism. Some years later, Haseena Lockhat brings the topic properly to the UK. She is primarily interested in circumcised women in the UK, and what is in store for their daughters. She brings a measured tone to a controversial topic

She clarifies the different forms of female genital mutilation; these vary in the extent to which part or all of the female external genitalia are removed. She places the practices in a cultural context, firmly refuting the idea that these practices are synonymous with Islam. Female genital mutilation is predominantly an African custom, but is far from ubiquitous in Africa. It has many purposes but seems most strongly linked with upholding traditional practices intended to guarantee chastity at marriage and to prevent a woman sexually straying thereafter.

UK law currently outlaws any form of female genital mutilation. This creates difficulties for migrant women in the UK who are circumcised and for families who want what they consider to be best for their daughters. Lockhat's careful documentation of the physical and psychological complications of female genital mutilation in UK residents leaves little room for sympathy for families that would put their daughters through what would normally be described as torture. Onethird of her sample explained that they were circumcised without anaesthetic, while being held down. Unsurprisingly many of her sample had symptoms of post-traumatic stress disorder. To compound the problems of these women, their experiences of healthcare in the UK were often poor. Neither their cultural mindset nor their bodily predicaments were well understood. They were equally unable to give voice to their unhappiness within their own community for fear of social disapproval.

This book will be valuable when clinical dilemmas arise either in relation to children or adult women and their families. It is not an easy read, nor should it be, given the difficulty and importance of the topic: 140 million women worldwide have been subjected to female genital mutilation, often as minors.

Annie Bartlett Senior Lecturer in Forensic Psychiatry, Department of Mental Health, St George's, University of London, CranmerTerrace, London SW17 ORE

\section{The Psychiatry of AIDS: A Guide to Diagnosis and Treatment}

Glenn J. Treisman \& Andrew F. Angelino (eds)

Baltimore: Johns Hopkins

University Press, 2004, f14.50 pb, 240 pp. ISBN: 0-8018-8006-8

This book aims to focus on clients with HIV whose conditions are complicated by mental health problems. It begins with a detailed history of HIV/AIDS, highlighting the impact of highly active anti-retrovira treatment (HAART) on improving survival rates. It then looks at adherence, which is frequently compromised by complicated medical regimens, side-effects, risktaking behaviours and mental health problems. Although the book is intended for HIV/AIDS professionals, it would be equally suitable for those outside the field, given the broad discussions of the main clinical issues, practical advice and recommendations.

The book offers a detailed description of behavioural observations during psychometric assessments, particularly those associated with AIDS-related dementia, together with suggestions for assessment questions and recommendations for cognitive tests, specific treatment plans and relapse prevention strategies. These discussions are supported by case studies, which reflect the multidimensional treatment approach often necessary for those with HIV whose conditions may be associated with depression, anxiety disorders, sexual difficulties, psychosis, personality disorder, addictions or neuropathology, and the professional and medical dilemmas involved with this group.

The authors emphasise the importance of developing a systemic understanding of cognitive functioning, social and recreational activities and environmental influences, which might affect a patient's condition. However, they fail to consider the benefits of multidisciplinary working in this regard. For example, most if not all UK-based HIV services employ nurse specialists and health advisors who provide expertise and advice about adherence; clinical psychologists also frequently treat clients presenting with mental health problems and nonadherence. It is noteworthy that the book focuses on the American healthcare system, so one wonders whether the omission with regards to multidisciplinary teamwork reflects a difference in service provision between the USA and the UK. Nevertheless, this book is useful as an overview of the issues that challenge clinicians working in HIV and is written in a thoughtful and readable style, which would appeal to a wide readership. 